\title{
Psicologias Sociais Cientificista e Crítica: Um Debate que Continua
}

\author{
"Scientificist" And "Critical" Social Psychologies: \\ A Debate That Goes On \\ Psicologías Sociales "Cientificista" Y "Crítica": \\ Una Debate Que Continúa
}

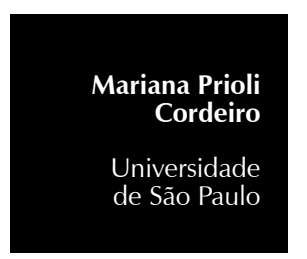

Esse trabalho

contou com apoio do Conselho Nacional de Desenvolvimento Científico e Tecnológico (CNPq). 
1Muitos(as)

pesquisadores(as)

da TAR utilizam

técnicas etnográficas tradicionais para seguir os atores que fazem parte de uma rede.

Acompanham ao vivo o surgimento e o desaparecimento de vínculos e associações entre atores heterogêneos; falam, portanto, do presente.

No entanto, isso não quer dizer que

as ideias propostas pela TAR não possam servir para pensar sobre o passado o próprio Latour realizou pesquisas sobre controvérsias científicas bastante antigas. Além disso, no presente trabalho, não buscamos contar a história da Psicologia

social brasileira tal como os historiadores a fariam, mas,

assim como Latour, buscamos usar a

história "como um neurocientista usaria um rato" (1998, p.

12), abrindo seu corpo para seguir os mecanismos que nos permitem compreender os conteúdos e os contextos de uma ciência. "Por essa razão, a apresentação de materiais

documentais não segue o caminho proposto pela

História, mas a rede de associações que lentamente fazem o mundo" (1998, p.12).

Resumo: Diversos autores falam de ao menos duas versões da Psicologia social: uma anterior e outra posterior à crise de referência que assolou essa área do conhecimento na década de 70. A primeira tinha uma base positivista, já a segunda se caracterizava por defender uma ciência comprometida com a transformação social. Em geral, esses textos narram a história da Psicologia social destacando personagens, acontecimentos e ideários. Neste artigo, seguindo a proposta da teoria ator-rede, acrescentamos novos elementos a essa história e falamos dos atores humanos e não humanos, das materialidades e socialidades, que contribuíram para construir a Psicologia social brasileira. Concluímos o texto argumentando que a crise de referência não eliminou por completo a Psicologia social positivista, substituiu-a por uma vertente crítica, pois, ainda hoje, ambas coexistem. Argumentamos, portanto, que a Psicologia social brasileira é complexa, e que essa complexidade não cabe na tênue linha do tempo que muitas vezes traçamos para representar o desenvolvimento de disciplinas acadêmicas.

Palavras-chave: Psicologia social - história. Psicologia marxista. Psicologia experimental. História da ciência.

Abstract: Many authors discuss about at least two versions of social psychology: one previous and the other posterior to the reference crisis which characterized this area of knowledge in the 70s. The first one had a positivist basis and the second one was committed to transform the society. Most of the times, those texts narrate the history of social psychology highlighting characters, facts and ideas. In this paper, following the methodology proposed by the actor-network theory, we added new elements to this history and discussed the human and non-human actors, the materialities and socialities that contributed to build the Brazilian social psychology. We conclude the text arguing that the reference crisis didn't eliminate completely the positivist social psychology but substituted it for the "critical" one, because both coexist until today. Therefore, we argue that Brazilian social psychology is complex and that this complexity doesn't fit into those tenuous time lines we often use to represent the development of academic disciplines.

Keywords: Social psychology - history. Marxist psychology. Experimental psychology. History of science.

Resumen: Diversos autores hablan de al menos dos versiones de la Psicología Social: una anterior y otra posterior a la crisis de referencia que asoló esta área del conocimiento en la década de 1970. La primera tenía una base positivista, ya la segunda se caracterizaba por defender una ciencia comprometida con la transformación social. En general, esos textos narran la historia de la Psicología Social destacando personajes, acontecimientos e idearios. En este artículo, siguiendo la propuesta de la Teoría Actor-Red, agregamos nuevos elementos a esa historia y hablamos de los actores humanos y no humanos, de las materialidades y socialidades, que contribuyeron para construir la Psicología Social brasilera. Concluimos el texto argumentando que la crisis de referencia no eliminó por completo la Psicología Social "positivista" y la substituyó por la "crítica", pues, aún hoy, ambas coexisten. Argumentamos, por lo tanto, que la Psicología Social brasilera es compleja, y que esta complejidad no cabe en la tenue línea del tiempo que muchas veces trazamos para representar el desarrollo de disciplinas académicas.

Palabras clave: Psicología social - historia. Psicología marxista. Psicología experimental. Historia de la ciencia.

Diversos textos introdutórios à Psicologia social brasileira (Bernardes, 2007; Bock \& Furtado, 2007; Ferreira, 2011; Mancebo, Jacó-Vilela, \& Rocha, 2003; Tittoni \& Jacques, 2001) falam de ao menos duas versões dessa disciplina: uma anterior e outra posterior à crise de referência que atingiu essa área do conhecimento na década de 70. Segundo esses autores e autoras, a primeira era marcada pela hegemonia da Psicologia social norte-americana, tinha uma base positivista e Aroldo Rodrigues era seu principal representante brasileiro. A segunda, por sua vez, caracterizava-se por fazer uma severa crítica ao modelo biologicista e, principalmente, por defender uma ciência comprometida com a transformação social.

Em geral, esses textos narram a história da Psicologia social destacando personagens, acontecimentos e ideários. Neste artigo, seguindo a proposta de autores da teoria atorrede (TAR) (Latour, 2008; Law, 1992; Mol \& Law, 2002), acrescentaremos novos elementos a essa história e falaremos, também, de livros, instrumentos, escalas, transcrições, etc ${ }^{1}$, ou seja, falaremos dos atores humanos e não humanos, das materialidades e socialidades, que contribuíram para construir a Psicologia social que temos nos dias de hoje. 
Ao optar por seguir essa postura teóricometodológica, partiremos do pressuposto de que a realidade não é um fato externo, objetivo e sujeito à interpretação cultural da ciência. Pelo contrário, é algo construído e reconstruído ativamente. E, para descrever como ocorre esse processo de construção e de reconstrução, focaremos na heterogeneidade material das redes de atores humanos e não humanos que compõe essa realidade e a descreveremos a partir de uma ontologia relacional. Em outras palavras, partiremos do pressuposto de que só podemos falar do real ao nos referirmos a uma multiplicidade de materiais heterogêneos conectados em forma de uma rede que tem múltiplas entradas, está sempre em movimento e aberta a novos elementos que podem se associar de forma inédita e inesperada. Todos os fenômenos são efeitos dessas redes que mesclam simetricamente pessoas e objetos, dados da natureza e dados da sociedade, oferecendoIhes igual tratamento (Melo, 2007, p. 170).

Oferecer-lhes igual tratamento não significa estabelecer a priori o que é social, o que é natural ou o que é tecnológico, significa não estabelecer uma hierarquia ou uma ordem de prevalência entre os atores de uma rede, significa considerar que qualquer coisa - pessoa ou objeto - cuja incidência modifique um estado de coisas seja um ator (Latour, 2008).

É importante ressaltarmos que dizer que os não humanos participam da história da Psicologia social não significa dizer que eles a determinam. Afinal, segundo Latour, existem muitos matizes metafísicos entre a plena causalidade e a mera inexistência: além de "determinar", ou de "servir como pano de fundo da ação humana", as coisas podem autorizar, permitir, sugerir, dar recursos, influenciar, proibir, bloquear, etc. Sendo assim, os autores da TAR não propõem a afirmação vazia de que são os objetos - e não os atores humanos - que fazem as coisas; dizem, simplesmente, que nenhuma ciência do social pode existir se não explorar, primeiramente, a questão do que e de quem participa da ação - ainda que isso signifique permitir que se incorporem elementos não humanos à resposta.

Também é importante ressaltarmos que dizer que não há diferença fundamental entre pessoas e objetos é uma atitude analítica, e não uma posição ética. Afinal, segundo Law, isso não significa que tenhamos de tratar as pessoas como máquinas ou que tenhamos de negar os direitos, deveres e responsabilidades que usualmente lhes atribuímos, mas que podemos usar essa atitude "para aprofundar questões éticas sobre o caráter especial do efeito humano - como, por exemplo, em casos difíceis tais como os de vida mantida artificialmente por causa das tecnologias de tratamento intensivo" (1992, p. 4).

Trataremos, portanto, da chamada crise de referência da Psicologia social brasileira como efeito das associações entre uma série de elementos heterogêneos. Esses elementos, humanos e não humanos, não estão localizados apenas no Brasil, nem pertencem apenas ao campo psicossocial. Afinal, o movimento de abalo teórico que marcou essa área do conhecimento marcou também a Sociologia das décadas de 60 e de 70. Nesse período, a Sociologia europeia traduzia, sobretudo, o declínio do impulso modernizante do pós-guerra (Lallement, 2008), enquanto, na América Latina, ela traduzia a repressão políticocultural dos regimes ditatoriais (Liedke Filho, 2005). A guerra e o autoritarismo levaram ao enfraquecimento da fé na igualdade de oportunidades e ao esgotamento das garantias de coesão social pelo simples crescimento econômico, fazendo com que instituições como a escola, a prisão e a fábrica - fossem questionadas, favorecendo, com isso, o fortalecimento das correntes neomarxistas. 
2 Com o fortalecimento dessas teorias e metodologias, começou a pensar-se na necessidade de criar uma associação que representasse as novas Psicologias sociais. De acordo com Lane e Bock (2003), essa necessidade foi

bastante discutida durante o congresso da SIP de 1979, sendo que, logo após o evento, foi nomeada uma comissão para redigir o estatuto dessa nova associação. No ano seguinte, durante a reunião anual da Sociedade Brasileira para o Progresso da Ciência (SBPC), esse estatuto foi votado e aprovado, instituindo oficialmente a

Associação Brasileira de Psicologia

Social (ABRAPSO). Segundo as autoras, as intenções políticas da ABRAPSO sempre foram "a construção de uma psicologia social crítica, voltada para os problemas nacionais, que acatasse diferentes correntes epistemológicas, desde que filiadas ao compromisso social de contribuir para a construção de uma sociedade mais justa. A ABRAPSO nasceu da insatisfação com a psicologia européia e americana. Os problemas de nossa sociedade, marcada pela desigualdade social e pela miséria, não encontravam soluções na psicologia social importada como

um saber universal dos países do Primeiro Mundo" (p. 149).
Segundo Lane, nesse mesmo período, a eficácia da Psicologia social norteamericana começou a ser problematizada pelos europeus. Na França, por exemplo, a tradição psicanalítica foi retomada com toda a veemência após o movimento de maio de 68, e a tradição norte-americana foi criticada por ser "uma ciência ideológica, reprodutora dos interesses da classe dominante, e produto de condições históricas específicas" (2001, p. 11). Esse movimento repercutiu na Inglaterra, "onde Israel e Täjfell analisaram a 'crise' sob o ponto de vista epistemológico com os diferentes pressupostos que (embasavam) o conhecimento científico - (era) a crítica ao positivismo, que, em nome da objetividade, (perdia) o ser humano" (2001, p. 11).

Segundo Bernardes (2007), a despeito de ter abalado os princípios da Psicologia europeia na década de 60, essa crise de referência começou a fortalecer-se no Brasil e em outros países da América Latina com uma década de atraso, principalmente durante os congressos da Sociedade Interamericana de Psicologia (SIP), como nos realizados em Miami-EUA (1976) e em Lima-Peru (1979). De acordo com o autor, os principais motivos de insatisfação foram: a dependência teórico-metodológica, principalmente dos Estados Unidos, a descontextualização dos temas abordados, a superficialidade e a simplificação das análises desses temas, a individualização do social e a ausência de preocupação política.

De acordo com Jacó-Vilela (2007), essas insatisfações levaram ao desenvolvimento e/ou à adoção de diferentes teorias e metodologias: um grupo de pesquisadores, liderado por Ângela Arruda e Celso Sá, começou a realizar trabalhos a partir de teorias europeias, especialmente a das representações sociais; outro grupo, liderado por Lapassade, Saidón e Barenblit, desenvolveu a análise institucional; já Silvia Lane coordenou o grupo que estabeleceu os fundamentos do que mais tarde viria a ser conhecido como a escola socio-histórica da PUC-SP².

São justamente as diferenças entre essa escola fundada por Lane e a corrente norteamericana defendida por Rodrigues o foco deste artigo. Optamos por fazer esse recorte por duas razões principais: primeiramente, pela inviabilidade de descrever todas as psicologias sociais criadas no Brasil a partir da década de 70, e, em segundo lugar, pelo fato de alguns autores (como Strey et al., 2007; Lima, 2009; Sá, 2007, entre outros) se referirem a Lane como uma das principais opositoras do modelo positivista defendido por Rodrigues.

No entanto, diferentemente da maioria dos textos sobre a história da Psicologia social brasileira, não focaremos nossa análise exclusivamente em divergências epistemológicas e/ou éticas, mas consideraremos, também, as práticas que há décadas vêm caracterizando essas duas psicologias sociais. Em um primeiro momento, analisaremos textos que descrevem pesquisas realizadas ou orientadas por Rodrigues e Lane e apontaremos algumas diferenças fundamentais dessas duas maneiras de fazer pesquisa em Psicologia social (tópico 1). Em um segundo momento, identificaremos alguns dos usos que os trabalhos desses autores possuem nos dias de hoje. Com isso, procuramos discutir em que medida a crise de referência representou uma mudança radical de paradigmas (tópico 2).

\section{As psicologias sociais de Aroldo Rodrigues e de Silvia Lane}

A Psicologia social de Rodrigues (1972) consiste em realizar um estudo científico do processo de interação humana, ou seja, é uma ciência básica cuja única forma de intervenção é indireta: ela fornece dados 
"Dessa forma, conscientes ou não, sempre a pesquisa implica intervenção, ação de uns sobre outros" (Lane, 2001, p. 18). objetivos para que tecnólogos sociais possam resolver problemas sociais. Nas palavras do autor,

$$
\begin{aligned}
& \text { o tecnólogo social se fundamenta nos } \\
& \text { dados existentes, combina-os e, através de } \\
& \text { sua criatividade, utiliza-os na resolução de } \\
& \text { problemas sociais. Como bem diz Jacobo } \\
& \text { Varela, o inventor da tecnologia social, } \\
& \text { 'tecnologia é síntese, enquanto ciência, é } \\
& \text { análise'... a Psicologia social é uma ciência } \\
& \text { básica e... a ela cabe descobrir as relações } \\
& \text { estáveis entre variáveis psicossociais a } \\
& \text { fim de possibilitar ao tecnólogo social a } \\
& \text { solução de problemas sociais de forma } \\
& \text { consciente e não improvisada (Rodrigues, } \\
& \text { 1985, pp. 19-20) }
\end{aligned}
$$

Sendo assim, a essa Psicologia social caberia o papel de estudar, através do método científico, a interação humana e suas consequências cognitivas e comportamentais, enquanto a tecnologia social seria responsável por usar esse conhecimento para transformar a realidade. Nessa Psicologia social, estudar um determinado fato a partir do método científico significa orientar-se pelo seguinte esquema: em um primeiro momento, partese de uma teoria para levantar hipóteses. Em seguida, testam-se as hipóteses levantadas e analisam-se os dados colhidos. Por fim, confirmam-se ou rejeitam-se as hipóteses iniciais (Rodrigues, 1972).

De acordo com o autor, esse esquema deve ser marcado pela neutralidade do(a) psicólogo(a) social em sua procura pelas relações não aleatórias entre variáveis. Apesar de Rodrigues admitir que a escolha do tema e o relatório do cientista podem não ser neutros, para ele, "o produto final, isto é, o conhecimento novo que surge, esse é inexoravelmente neutro, pois toda a comunidade científica o fiscaliza" (1985, p. 19).

Contrariamente a Rodrigues, Lane critica a defesa da neutralidade da ciência e da objetividade dos fatos. Sendo assim, a
Psicologia social de suas pesquisas e livros resgata a subjetividade, e não vê o indivíduo como produto de si mesmo. Em suas palavras:

se a Psicologia apenas descrever o que é observado ou enfocar o Indivíduo como causa e efeito de sua individualidade, ela terá uma ação conservadora, estatizante - ideológica - quaisquer que sejam as práticas decorrentes. Se o homem não for visto como produto e produtor, não só de sua história pessoal mas também da história de sua sociedade, a Psicologia estará apenas reproduzindo as condições necessárias para impedir a emergência das contradições e a transformação social (Lane, 2001, p. 15)

Sendo assim, o homem a que a autora se refere é diferente do que aparece nos textos de Rodrigues. Considerar o ser humano dessa maneira implica uma atuação mais consequente da Psicologia, na qual teoria e prática devem andar sempre juntas (Lane, 1985). Em outras palavras, implica que o conhecimento seja compreendido, antes de tudo, como práxis.

Considerar a Psicologia social como práxis significa, segundo Lane, abrir mão da busca pela neutralidade científica. Afinal, em sua ciência, tanto o pesquisador quanto o pesquisado são, ao mesmo tempo, produtos e agentes histórico-culturais, e definem-se por meio de relações sociais que tanto podem reproduzir as condições sociais em que ambos estão inseridos quanto podem transformá-las. “Dessa forma, conscientes ou não, sempre a pesquisa implica intervenção, ação de uns sobre outros" (Lane, 2001, p. 18).

Segundo Rodrigues (1989), essa ênfase na práxis e no compromisso social do(a) pesquisador(a) foi o principal desencadeador da crise que atingiu a Psicologia social em meados da década de 70. De acordo com o autor, a gravidade dos problemas sociais da época gerou certo sentimento de culpa nos psicólogos sociais, o que fez 
com que abandonassem o paradigma clássico e buscassem outra orientação teórico-metodológica, passando, assim, da ciência básica para um movimento articulado de ação social. Entretanto, na opinião de Rodrigues $(1979,1989)$, essa crise foi artificial, desnecessária e trouxe consequências nefastas para a Psicologia social.

Além disso, segundo o autor, essa crise só ocorreu devido à ignorância da distinção entre ciência e tecnologia. Para ele, assim como fisiólogos não curam doentes, ou físicos não constroem pontes e casas, psicólogos sociais não são os responsáveis por mudar a realidade social. Seu papel é o de produzir conhecimento, sendo que a aplicação desse conhecimento e a resolução de problemas concretos são tarefas dos tecnólogos sociais.

Em um texto autobiográfico, Rodrigues nos dá um bom exemplo dessa controvérsia que balançava a Psicologia social brasileira nas décadas de 60 e de 70 . Nesse texto, o autor conta que, quando voltou ao Brasil após ter passado quatro anos nos Estados Unidos fazendo seu doutorado, percebeu que seus alunos e colegas demonstravam pouco interesse pelas pesquisas que acabara de realizar, tanto que, quando ministrou uma conferência acerca de sua tese em um encontro da Associação Brasileira de Psicologia Aplicada, nenhuma pessoa da plateia fez questões ou comentários. Havia um total silêncio, até que um dos membros da diretoria da Associação se levantou e disse: "Professor Rodrigues, seu trabalho é muito elegante e sofisticado, mas diga-me, qual a aplicação prática de tudo isso? Qual uso podemos fazer de suas descobertas na realidade brasileira?" (Rodrigues, 2008, p. 112, tradução nossa). Nesse momento, Rodrigues percebeu que

estava no lugar errado, na hora errada. Os psicólogos brasileiros não estavam interessados em teoria e metodologia, mas em aplicações da Psicologia que permitissem melhorar as condições das pessoas e resolver problemas sociais. Em outras palavras, a crise da Psicologia social estava manifestando-se com toda a força no Brasil. O ceticismo em relação a experimentos em Psicologia social, muitas preocupações éticas e o quase exclusivo interesse na Psicologia social aplicada eram as posições dominantes (Rodrigues, 2008, p. 112)

Segundo o autor, a situação política que o Brasil vivia na época era bastante favorável ao desenvolvimento dessa nova psicologia social, pois o interesse pelo marxismo, a ênfase na pesquisa-ação e o desejo de mudar a estrutura social eram predominantes entre os universitários. Mas como Rodrigues discordava da fusão entre ciência e política, e como foram frustrados seus esforços para fazer com que seus colegas percebessem que ciência e tecnologia eram áreas distintas, em 1968, ele resolveu voltar aos Estados Unidos, onde passou a lecionar na Claremont Graduate School.

Em entrevista concedida ao Conselho Federal de Psicologia (CFP), Lane fala claramente das diferenças entre sua Psicologia social e a de Rodrigues:

Na ANPEPP de Gramado, o Aroldo Rodrigues me chama para falar de minha linha teórica. E no encontro anterior, na Venezuela, ele disse que eu não fazia ciência, eu fazia política... Eu preparei um texto para falar em Gramado só em cima de resultados de pesquisa, do pessoal que eu conhecia, quer dizer, mais prova de que a coisa tem uma consistência científica não é possível (2007, s.p.)

Uma das pesquisas que Lane mencionou durante sua conferência nesse simpósio da Associação Nacional de Pesquisa e Pós-Graduação em Psicologia (ANPEPP) tinha como objeto de estudo a consciência de sujeitos gagos. A despeito de não ter explicitado sua autoria, acreditamos que 
ela se referia à tese de doutorado de Silvia Friedman, uma de suas orientandas. Nesse trabalho - defendido em 1992 e publicado em 1994 - Friedman estudou as mudanças no movimento da consciência ao longo de um tratamento terapêutico. Para isso, apoiou-se em conceitos como consciência, linguagem e representações sociais, e em autores como Leontiev, Luria, Vigostski, Moscovici, Spink, Jodelet e na própria Silvia Lane. O corpus da pesquisa foi composto pela gravação e transcrição de algumas sessões terapêuticas que Friedman realizou em sua clínica de fonoaudiologia, e a técnica empregada foi a análise gráfica do discurso.

Segundo Friedman (1994), essa técnica foi desenvolvida por Lane e compreende algumas etapas: em primeiro lugar, é feita uma numeração das unidades de significados ou dos conteúdos que compõem o discurso - que geralmente correspondem a um sujeito e a seu predicado -, acompanhando a sequência em que aparecem. Em um segundo momento, são realizadas releituras cuidadosas do material estudado, buscando localizar e marcar os significados que se repetem. Essa etapa é importante, uma vez que

as unidades de significado ou as representações que se repetem são os núcleos de pensamento que expressam os conteúdos da consciência do indivíduo... Um discurso suficientemente longo e detalhado permite analisar tanto as representações como as mudanças que elas sofrem, as contradições, os aspectos ideológicos, as relações estabelecidas com os domínios da realidade, revelando, assim, o movimento da consciência do indivíduo (Friedman, 1994, p. 22)

Para facilitar a identificação dos núcleos de pensamento que compõem os discursos estudados, marca-se com cores diferentes cada conjunto de conteúdos semelhantes. Na terceira etapa, a fim de tornar mais claras as representações que compõem os núcleos de pensamento, bem como o movimento de articulação entre os núcleos, o discurso é reescrito, aproximando graficamente as representações que compõem um mesmo núcleo, e preservando, por meio de setas numeradas, a sequência original do discurso. Por fim, são identificados os conjuntos de núcleos de pensamento que pertencem a um mesmo núcleo temático, considerando que

as articulações entre as representações, que evidenciam as articulações entre os núcleos, evidentemente esclarecem também as articulações entre as categorias. A partir delas (analisa-se) os conteúdos da consciência e seu movimento, chegando à compreensão dos processos subjacentes à produção do fenômeno investigado (Friedman, 1994, p. 23)

Podemos dizer, assim, que as práticas descritas nessa tese orientada por Lane fazem uma Psicologia social que depende de uma série de elementos heterogêneos, tais como autores russos, livros sobre a teoria das representações sociais, gravadores de voz, transcrições, jogos de canetas hidrográficas coloridas, setas numeradas, núcleos de pensamento, discursos, uma consciência que se move, notas de leitura, notas de releitura, representações gráficas do discurso, etc. Juntos, esses atores nos permitem falar do que a Psicologia social é.

Na tese de Friedman, a Psicologia social é algo bastante diferente do que ela é em uma pesquisa de Rodrigues e Assmar (2003) sobre comportamento normativo. Nesse estudo, os autores estudam "a situação em que o comportamento representa uma transgressão às normas vigentes, e a pessoa que é solicitada a emiti-lo recusa-se de início a fazê-lo, cedendo, posteriormente, à influência exercida pelo influenciador" (Rodrigues \& Assmar, 2003, p. 191).

Os autores consideram esse fenômeno tipicamente psicossocial, uma vez que consiste na "consideração do poder da 
situação social na modificação de um comportamento" (Rodrigues \& Assmar, 2003, p. 191), e, para estudá-lo, baseiamse, principalmente, em dois referenciais teóricos: na tipologia das bases do poder social, proposta por Raven, e na teoria da conduta social, de Weiner.

Como procedimento metodológico, os autores aplicaram um questionário a 84 estudantes de uma universidade do Rio de Janeiro, sendo que a 42 deles apresentaram previamente um cenário com desfecho positivo e, aos outros 42, apresentaram um desfecho negativo. O primeiro cenário consistia na seguinte história:

uma enfermeira recebeu um telefonema de um médico, solicitando-lhe que desse quatro pílulas de um remédio, que estava ainda em fase experimental, a um de seus pacientes. Como isso contraria o código de ética das enfermeiras, ela se recusou a fazê-lo. O médico insistiu e apresentou uma razão para que a enfermeira fizesse o que ele queria. A enfermeira acabou por fazer o que o médico lhe pediu. No dia seguinte, o paciente teve notável recuperação e foi para casa alguns dias depois (Rodrigues \& Assmar, 2003, p. 193)

Já para os estudantes que estavam no grupo desfecho negativo, as instruções eram as mesmas; o que variava era apenas o final da história, que dizia:

a enfermeira acabou por fazer o que o médico lhe pediu. No dia seguinte, o paciente piorou muito e veio a falecer alguns dias depois.

Nas páginas seguintes, seguiam-se seis razões apresentadas pela enfermeira para fazer o que o médico lhe disse, cada uma representando uma das seis bases de poder da tipologia de Raven (1965). Essas razões, apresentadas em seguida, correspondem respectivamente, ao poder de recompensa, de coerção, de legitimidade, de referência, de conhecimento e de informação: a) o médico disse à enfermeira que facilitaria as coisas para ela no futuro, b) o médico disse que cortaria o salário da enfermeira em $\mathrm{R} \$$ 50,00 por mês, durante cinco meses, c) o médico disse que, nas organizações decentes, as ordens superiores devem ser seguidas, d) o médico disse que tinha sido sempre uma referência positiva para ela, e) o médico disse que ela deveria fazer o que Ihe foi solicitado, pois ele era visto por todos como um especialista, f) o médico disse que os médicos dos principais hospitais do País estavam usando o remédio (Rodrigues \& Assmar, 2003, p. 193)

Esses contextos eram seguidos por escalas de nove pontos, que mediam o grau de controlabilidade, de internalidade e de responsabilidade atribuídos à enfermeira. Essas escalas eram ancoradas nas extremidades pela indicação de totalmente interno/totalmente externo, sob controle da enfermeira/fora de seu controle e muito responsável/nada responsável.

Para evitar que as frases que representavam as bases de poder tivessem forças diferentes, os autores realizaram um estudo prévio, apresentando a 60 participantes (distintos dos 84 que participaram da pesquisa propriamente dita) 6 conjuntos de 10 frases, cada um representativo de uma das seis bases de poder da tipologia de Raven e relacionado à interação médico-enfermeira descrita nos cenários. As frases eram apresentadas em ordem aleatória, e os participantes tinham de indicar em uma escala de 11 pontos quão forte eles consideravam a tentativa de influência descrita em cada frase. Em seguida, era calculado o valor escalar de cada frase. Se acontecesse de mais de uma frase ter o mesmo valor escalar, os autores escolhiam a que tinha o menor desvio-padrão. "Dessa forma, seis frases com idênticos valores escalares para as formas de influência do Grupo 1 (recompensa, informação e referência) e para as do Grupo 2 (conhecimento, legitimidade e coerção) foram selecionadas e utilizadas na segunda fase da pesquisa" (Rodrigues \& Assmar, 2003, p. 194). A fim de evitar um possível efeito da ordem de apresentação dessas frases, os autores construíram aleatoriamente seis ordens de 
apresentação em um quadrado latino, sendo que este foi replicado sete vezes em cada condição.

$\mathrm{O}$ instrumento utilizado nessa pesquisa continha outra série de itens: ele solicitava que os participantes supusessem que o diretor do hospital havia demitido a enfermeira que havia ministrado o remédio experimental, e, em seguida, apresentava seis escalas de sete pontos, uma para cada motivo alegado pela enfermeira para fazê-lo (promessa de recompensa, ameaça de punição, invocação de legitimidade, amizade, conhecimento e apresentação de argumentos). Nessas escalas, os participantes indicavam, primeiramente, o grau de justiça da decisão do diretor do hospital de demiti-la, e, em seguida, indicavam o grau de justiça da não aplicação de algum tipo de punição. Indicavam, também, o grau de justiça de aplicação da punição, independentemente do motivo, e, por fim, hierarquizavam as razões para cometer a infração, sendo que a classificação 1 se referia à merecedora de maior, e a 6, à merecedora da menor punição.

A Psicologia social desta pesquisa não estuda consciência nem discursos, não se baseia na obra de autores russos nem de franceses, não articula núcleos de pensamento nem unidades de significados, não grava nem transcreve. Ela é uma Psicologia social que tem como objeto os graus de justiça da punição de comportamentos infratores e, para analisálos, usa estatísticas, questionários, escalas, tipologias de bases de poder, frases, cenários, valores escalares, desvios-padrão, réplicas de estudos, classificações, quadrados latinos, salas de aula, estudantes universitários dispostos a participar de pesquisas científicas, uma enfermeira, um médico, um remédio experimental, um paciente que é curado de sua doença, outro que vem a falecer...

Mas não é somente em pesquisas que essas psicologias sociais se chocam. Nas intervenções, também há diferenças. Como dissemos anteriormente, Rodrigues sustenta que o tecnólogo social deve ser o responsável por intervir nos problemas sociais, enquanto Lane sustenta que teoria e prática devem sempre andar juntas. Um exemplo de como essa controvérsia é vivida na prática está no depoimento cedido por Wanderley Codo à revista Psicologia: Ciência e Profissão. O autor - que foi orientando de doutorado de Silvia Lane - nos conta que o dirigente de uma determinada empresa decidiu demitir um de seus gerentes e escolheu uma pessoa de outra filial para preencher a vaga, o que causou mal-estar entre os funcionários preteridos para o cargo. Para amenizar os possíveis traumas dessa transição, a empresa contratou um cientista. Entretanto, para Codo,

qualquer pessoa de bom senso saberia que as causas desse problema estão na estrutura alienada de trabalho na sociedade contemporânea - que permite aos diretores alterar ao seu bel prazer os quadros de profissionais da empresa sem que os próprios tenham direito a opinar sobre isso - e nas características do mercado capitalista, em que a competição frenética angustia qualquer trabalhador numa perspectiva de mudança. $\mathrm{O}$ que fez o senhor Varela? Tratou de persuadir os trabalhadores, candidatos naturais para o cargo, de que não eram as pessoas mais aptas para aquele cargo. Estamos diante de um duplo engodo: nem a realidade social cabe no receituário do tecnólogo e muito menos as soluções encontradas são capazes de resolver qualquer coisa, exceto o problema imediato do dirigente empresarial. Estamos diante de uma tecnologia social sem dúvida voltada para encobrir os problemas sociais e a serviço dos meios de produção... Eis algo em que concordo literalmente com Jacobo Varela: o mundo está carente de uma tecnologia social. Mas que seja capaz de resolver não apenas querelas administrativas das empresas, mas, principalmente, capaz de instrumentalizar o cidadão para a busca de sua própria cidadania $(1985$, p. 21)

Nesse exemplo, podemos ver claramente que a divergência entre esses dois grupos de 
pesquisadores não está somente na defesa ou na crítica da dicotomia teoria/prática, mas está também no posicionamento acerca do compromisso político do pesquisador. Se, para o grupo de Lane $(1985,2001)$, o psicólogo social é aquele que busca transformar a realidade, no de Rodrigues, "o único engajamento admissível em ciência é... o compromisso desinteressado, objetivo e persistente na busca da verdade acessível ao arsenal metodológico disponível" (1989, p. 129).

Outra importante diferença entre essas psicologias sociais refere-se ao posicionamento em relação à universalidade da ciência. Para Lane,

o saber humano não é universal nem eterno, e o homem é historicamente situado, bem como os problemas que o afligem. Portanto, a realidade social não pode ser compreendida por teorias importadas, seja dos Estados Unidos, seja da Europa. É preciso conhecer quem é o homem que se constitui nas condições sócio-históricas da América Latina. Não se trata de abandonar o acervo teórico acumulado árdua e rigorosamente pela Psicologia social, mas de mudar a sensibilidade epistemológica para rever-se à luz dos novos atores sociais, das necessidades, idéias e emoções que objetivam na atividade cotidiana (Lane \& Sawaia, 2006, p. 8)

Já Rodrigues discorda dessa ênfase na geração de teorias e métodos próprios a um país ou região. Apesar de não ser contra a produção de teorias e métodos novos na América Latina, o autor critica a ênfase dada à busca de idiossincrasias quando, a seu ver, a ciência deve procurar universais.

Essas controvérsias entre Lane e Rodrigues constituem um bom exemplo da diversidade de versões da Psicologia social brasileira. E é interessante notarmos que, mesmo após anos de debate, a caixa-preta ${ }^{3}$ não se fechou, muito pelo contrário, ambos os autores continuam sendo lidos e seus textos continuam compondo a lista de bibliografia básica de disciplinas acadêmicas e de concursos públicos.

\section{Um debate que continua}

O livro Psicologia Social, de Rodrigues, por exemplo, está na $28^{\mathrm{a}}$ edição ${ }^{4}$, e fez parte das listas de referências bibliográficas indicadas em vários editais recentes, como o edital n. 0 021/2008, do concurso público para professor efetivo na área de Psicologia Social, Organizacional e do Trabalho da Universidade Federal de Uberlândia (UFU), dos editais dos concursos para psicólogo da Prefeitura Municipal de Caraá - RS (n.. 008/2004) e da Prefeitura Municipal de Pitanga - PR (edital n. 01/2009), bem como do edital de seleção 2010.1 do mestrado em Psicologia Social da Universidade Federal da Paraíba (UFPB). Outro livro de Rodrigues bastante utilizado é Psicologia Social para Principiantes: Estudo da Interação Humana, que foi reeditado em 2010.

Os livros de Lane, como O que É Psicologia Social (Lane, 1981) e Psicologia Social: Homem em Movimento (Lane \& Codo, 1984/2001), também permanecem sendo reimpressos/ reeditados, estando, respectivamente, na $22^{a}$ e na $13^{\underline{a}}$ edição (7 $7^{a}$ e $5^{\underline{a}}$ reimpressão). Além disso, suas leituras também continuam a ser exigidas em concursos e processos seletivos, tais como o da Prefeitura Municipal de Reserva do Iguaçu - PR (edital n.o 01/2009) e o da Universidade Federal de Uberlândia UFU (edital n.․ 099/2009).

Os livros de Lane são, também, bibliografia básica de disciplinas introdutórias à Psicologia social de vários cursos de graduação, como, por exemplo, o da Universidade Federal de Santa Catarina (UFSC) (http://psicologia. ufsc.br/files/2012/02/ANDREA-ZANELLAPSI-7505-Psicologia-Social-II-2012.1.pdf) e o da Universidade Federal do Rio Grande 
do Norte (UFRN) (http://www.graduacao. ufrn.br/Programas/Psicologia/PSI0904\%20 -\%20T\%F3picos \%20em\%20Psicologia\%20 Social\%20I\%20.doc). Além disso, alguns cursos oferecem disciplinas voltadas especificamente para a Psicologia sociohistórica desenvolvida por Lane, como o Centro Universitário UNA (http://www.una. br/curso/graduacao/psicologia/grade) e a Universidade Luterana do Brasil (ULBRA) (http://www.ulbra.br/psicologia/files/matrizcurricular-psicologia.pdf).

Podemos dizer que o fato de as psicologias sociais de Lane e de Rodrigues coexistirem até os dias de hoje nos dá um forte indício da não linearidade da História. Ao contrário do que afirmam alguns autores, a crise de referência não representou um divisor de águas propriamente dito - afinal, ela não eliminou por completo a Psicologia social norte-americana e a substituiu por uma ciência dita politicamente comprometida. Além disso, ainda que possa diminuir sua hegemonia, uma ciência nunca substitui completamente a outra, pois aquilo que está reduzido ou esquecido em um momento pode ressurgir no momento seguinte, o que está em segundo plano pode, em seguida, passar a ser o foco de nossa atenção ( Mol \& Law, 2002).

Afora isso, o significado atribuído a uma nova teoria é estabelecido a partir da comparação desta com suas predecessoras - que, na maioria das vezes, não são descartadas, mas realocadas em uma esfera de ação ligeiramente diferente. Desse modo, o presente

não transcende o passado, mas o contém. $\mathrm{E}$, ao invés de ser uma unidade singular, o presente é composto de muitas partes. Há vários tempos diferentes dentro do presente: o antiquado e o precoce, o atual e o passageiro... Ao invés de fluir de uma maneira linear, o tempo assume a forma de dobras, voltas (loops) e espirais. É múltiplo. (Mol \& Berg, 1998, p. 5)
Segundo Annemarie Mol e John Law, muitos textos acadêmicos tendem a apresentar fenômenos complexos de uma forma simplificada. Eles elaboram esquemas baseados em uma lógica demonstrativa ou argumentativa que coloca um evento seguindo aquele que o precedeu. Como dissemos anteriormente, no caso da Psicologia social, esse esquema é usado para contar a história da disciplina de forma linear e dizer que a vertente crítica de Silvia Lane substituiu a corrente norte-americana de Aroldo Rodrigues. No entanto, "simplificações que reduzem uma realidade complexa a algo que cabe em um simples esquema tendem a 'esquecer' o complexo" (Mol \& Law, 2002, p. 3); elas tendem a considerá-lo algo perturbador e, em alguns casos, inclusive, a reprimi-lo.

É muito mais fácil (e, muitas vezes, mais aceito academicamente) apresentar uma área do conhecimento como algo ordenado, coerente e singular. Quando um aluno pergunta a um professor o que é Psicologia social, ele espera ouvir uma resposta rápida e objetiva: "Psicologia social é isso e ponto final". No entanto, conforme argumentamos neste artigo, uma área do conhecimento pode ter mais de uma versão: dissemos que, em alguns lugares, ela é positivista, enquanto, em outros, é politicamente comprometida. Mas poderíamos acrescentar muitos outros lugares e adjetivos a essa lista: poderíamos ter falado, por exemplo, de Psicologia social comunitária, institucional, psicanalítica, construcionista, do trabalho, da saúde, etc.

No entanto, dizer que uma área do conhecimento pode ter várias versões não significa dizer que essas versões não se relacionam. Afinal, para Mol e Law,

o tropo da ordem singular que reduz a complexidade... começa a perder seu poder quando a ordem é multiplicada, quando ordem se torna ordens. Quando investigadores começam a descobrir 
uma variedade de ordens - modos de ordenamento, lógicas, estruturas, estilos, repertórios, discursos -, a dicotomia entre o simples e o complexo começa a se dissolver. Isso se dá pois 'ordenamentos' diferentes de objetos, tópicos e campos similares nem sempre reforçam as mesmas simplificações ou impõem os mesmos silêncios... Isso levanta questões teóricas e práticas. Em particular, a descoberta da multiplicidade sugere que nós não mais vivemos em um mundo moderno, localizado dentro de uma única epistème. Ao invés disso, descobrimos que vivemos em mundos diferentes. Esses não são mundos... que pertencem, de um lado, ao passado e, de outro, ao presente. Ao invés disso, descobrimos que estamos vivendo em dois ou mais mundos vizinhos, mundos que se sobrepõem e coexistem. Multiplicidade refere-se, portanto, a coexistências em um único momento (2002, p. 7, grifos dos autores)

O fato de utilizarmos um mesmo nome para nos referirmos a uma série de práticas distintas é um indicativo dessa sobreposição e coexistência. A despeito de ocorrerem em locais distintos e de possuírem diferentes objetivos e modos de intervir, as diferentes versões da Psicologia social são chamadas da mesma maneira, são todas chamadas de Psicologia social. Esse rótulo funciona como uma espécie de ponte que une diferentes espaços e práticas, que cria semelhanças, que articula as realidades de um objeto múltiplo.

Essa articulação está presente tanto em políticas de formação e de fomento à pesquisa quanto em livros introdutórios e em associações profissionais: todos os cursos de graduação em Psicologia do País possuem ao menos uma disciplina voltada para a Psicologia social (Souza \& Souza Filho, 2009), a Capes reconhece cursos de pósgraduação stricto sensu na área, instituições de fomento dão bolsas a pesquisadores(as) que se autoidentificam como psicólogos(as) sociais, editoras publicam os livros desses(as) pesquisadores(as) e a ABRAPSO os(as) representa. Em todos esses espaços, o nome Psicologia social vincula uma série de práticas, referenciais teóricos e objetos de estudo.

\section{Considerações finais}

Neste artigo, argumentamos que, hoje, coexistem a psicologia social de Lane e a de Rodrigues. Coexistem a ciência básica que faz uso de laboratórios, experimentos e escalas para estudar o comportamento interpessoal - e a ciência politicamente comprometida e preocupada em entender como o ser humano se torna agente da História. Argumentamos, portanto, que a Psicologia social brasileira é complexa, e que essa complexidade não cabe na tênue linha do tempo que muitas vezes traçamos para representar o desenvolvimento de disciplinas acadêmicas. Além disso, argumentamos que, para contar a história da Psicologia social brasileira, não basta falar de personagens e de fatos, mas é preciso, também, falar de práticas, objetos, instrumentos... ou seja, é preciso falar dos atores humanos e não humanos que participaram da construção dessa história. Ao admitirmos que, em um campo do conhecimento, coexistem diferentes teorias, metodologias e objetos de estudo, nós admitimos ser complexa a realidade. E aprender a trabalhar com a complexidade, com a diversidade e com as controvérsias é tarefa inevitável da ciência crítica (Spink \& Cordeiro, 2009). 


\section{Mariana Prioli Cordeiro}

Doutora em Psicologia Social pela Pontifícia Universidade Católica de São Paulo e pós-doutoranda no Instituto de Psicologia da Universidade de São Paulo, São Paulo - SP - Brasil.

E-mail: mpriolicordeiro@gmail.com

Endereço para envio de correspondência:

Rua Dona Antônia de Queirós, 223, ap. 34, Consolação. CEP: 01037-010. São Paulo, SP.

Recebido 10/04/2012, 1aㅗ Reformulação 16/11/2012, Aprovado 11/04/2013. 


\section{Referências}

Bernardes, J. (2007). História. In M. N. Strey et al. Psicologia social contemporânea: livro-texto (10a ed., pp. 19-35). Petrópolis, RJ: Vozes (Trabalho original publicado em 1998).

Bock, A. M. B., Furtado, O. (2007). A psicologia no Brasil e suas relações com o marxismo. In A. M. Jacó-Vilela, A. A. L. Ferreira \& F. T. Portugal (Orgs.), História da psicologia: rumos e percursos (pp. 503-513). Rio de Janeiro: Nau.

Codo, W. (1985). Ideologia: o ponto fundamental da discussão. Psicologia: Ciência e Profissão, 5(1), 21. Recuperado em 15 fevereiro, 2009, de http://www.scielo.br.

Ferreira, M. C. (2011). Breve história da moderna psicologia social. In C. V. Torres \& E. R. Neiva (Orgs.), Psicologia social: principais temas e vertentes (pp. 13-30). Porto Alegre: Artmed.

Friedman, S. (1994). A construção do personagem bom falante. São Paulo: Summus.

Jacó-Vilela, A. M. (2007). O estatuto da psicologia social: contribuições da história da psicologia social. In C. Mayorga \& M. A. M. Prado (Orgs.), Psicologia social: articulando saberes e fazeres (pp. 37-54). Belo Horizonte, MG: Autêntica.

Lallement, M. (2008). História das idéias sociológicas: de Parson aos contemporâneos (3a ed., E. F. Alves, Trad.). Petrópolis, RJ: Vozes (Trabalho original publicado em 2000).

Lane, S. T. M. (2001). A psicologia social e uma nova concepção do homem para a Psicologia. In S. T. M. Lane \& W. Codo (Orgs.), Psicologia social: o homem em movimento (13a ed., pp. 10-19). São Paulo: Brasiliense (Trabalho original publicado em1984).

Lane, S. T. M. (2007). Silvia Lane: estilo em movimento (Entrevista a Carmem Silvia Taverna e Fernão Ciampa). Recuperado em 12 maio, 2009, de http://www.pol.org.br/pol/cms/pol/ publicacoes/videos/videos_070605_0171.html.

Lane, S. (1985). Revendo a prática da psicologia social (Entrevista). Psicologia: Ciência e Profissão, 5(1), 21. Recuperado em 15 fevereiro, 2009, do Pepsic (Periódicos Eletrônicos em Psicologia): http://pepsic.bvs-psi.org.br.

Lane, S. T. M. (1981). O que é psicologia social. São Paulo: Brasiliense.

Lane, S. T. M. \& Codo, W. (Orgs.). (2001). Psicologia social: o homem em movimento (13a ed.). São Paulo: Brasiliense (Trabalho original publicado em 1984).

Lane, S. T, M., \& Bock, A. M. B. (2003). Abrapso - uma história da psicologia social enquanto práxis. In A. M. Jacó Vilela, M. L. Rocha, M. L. \& D. Mancebo. (Orgs.), Psicologia social: relatos na América Latina. (pp. 145-155). São Paulo: Casa do Psicólogo.

Lane, S. T. M., \& Sawaia, B. B. (2006). Apresentação. In S. T. M. Lane \& B. B. Sawaia (Orgs.), Novas veredas da psicologia social (pp. 7-8). São Paulo: Brasiliense.

Latour, B. (1988). The pasteurization of France. Londres: Harvard University Press.

Latour, B. (2008). Reensamblar lo social: una introducción a la teoría del actor-red. (G. Zadunaisky, Trad.). Buenos Aires: Manantial.

Law, J. (1992). Notes on the theory of the actor network: Ordering, strategy and heterogeneity. Systems Practice, 5(1) 379-393. Recuperado em 12 novembro, 2009, do Center for Science Studies Lancaster University: http://www.lancs.ac.uk/ fass/sociology/papers/law-notes-on-ant.pdf

Liedke Filho, E. D. (2005). A sociologia no Brasil: história, teorias e desafios. Sociologias, 14(1), 376-437. Recuperado em 1 setembro, 2011, de http://www.scielo.br/

Lima, R. S. (2009). História da psicologia social no Rio de
Janeiro: dois importantes personagens. Fractal, 21(2), 409424.

Mancebo, D., Jacó-Vilela, A. M., \& Rocha, M. L. (2003). Psicologia social e história: um encontro necessário. In A. M. Jacó-Vilela, M. L. Rocha \& D. Mancebo (Orgs.), Psicologia social: relatos na América Latina (pp. 7-18). São Paulo: Casa do Psicólogo.

Melo, M. F. A. Q. (2007). Seguindo as pipas com a metodologia da TAR. Revista do Departamento de Psicologia da UFF, 19(1), 169-186.

Mol, A., \& Berg, M. (1998). Differences in medicine: An introduction. In M. Berg \& A. Mol (Eds.). Differences in medicine: unraveling practices, techniques and bodies (pp. 141-163). Durham: Duke University Press.

Mol, A., \& Law, J. (2002). Complexities: An introduction. In J. Law \& A. Mol. Complexities: Social studies of knowledge practices (pp. 1-22). Durham: Duke University Press.

Rodrigues, A (1972). Psicologia social. Petrópolis, RJ: Vozes.

Rodrigues, A. (1979). Estudos em psicologia social. Petrópolis, RJ: Vozes.

Rodrigues, A. (1985). Ciência e tecnologia a serviço do homem. (Entrevista). Psicologia: Ciência e Profissão, 5(1). Recuperado em 15 fevereiro, 2009, do Pepsic (Periódicos Eletrônicos em Psicologia): http://pepsic.bvs-psi.org.br.

Rodrigues, A. (1989). A psicologia social às vésperas de seu primeiro centenário. Simpósio Brasileiro de Pesquisa e Intercâmbio Científico da ANPEPP, 2 (pp. 117, 136). Recuperado em 15 julho, 2009, de http://www.infocien.org/ Interface/Simpos/An02T15.pdf.

Rodrigues, A. (2008). The full cycle of an interamerican journey in social psychology. In R. V. Levine, A. Rodrigues \& L. Zelezny (Eds.). Career journeys in social psychology (pp. 115-128). NewYork: Taylor \& Francis Group.

Rodrigues, A., \& Assmar, E. M. L. (2003). Influência social, atribuição de causalidade e julgamentos de responsabilidade e justiça. Psicologia: Reflexão e Crítica, 16(1), 191-201.

Sá, C. P. (2007). Sobre a psicologia social no Brasil: entre memórias históricas e pessoais. Psicologia \& Sociedade, 19(3), 7-13

Souza, L. C. G., \& Souza Filho, E. A. (2009). O lugar de psicologia social na formação dos psicólogos. Psicologia \& Sociedade, 21(3), 383-390.

Spink, M. J. P., \& Cordeiro, M. P. (2009). Psicologia social: a diversidade como expressão da complexidade. In M. R. Souza \& F. C. S. Lemos (Orgs.), Psicologia e compromisso social: unidade na diversidade. (pp. 219-234). São Paulo: Escuta

Strey, M. N. et al. (2007). Psicologia social contemporânea: livro texto (10a ed.). Petrópolis, RJ: Vozes (Trabalho original publicado em1998).

Tittoni, J., \& Jacques, M. da G. C. (2007). Pesquisa. In M. N. Strey et al. Psicologia social contemporânea: livro texto (10a ed., pp. 73-85). Petrópolis, RJ: Vozes. 